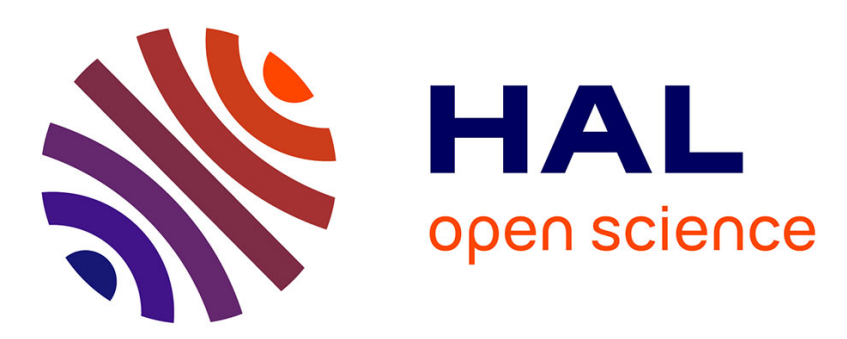

\title{
Alignment of centers of mass of body segments with the gravity line
}

Célia Amabile, Agathe Nerot, Julie Choisne, Hélène Pillet, Virginie Lafage, Wafa Skalli

\section{- To cite this version:}

Célia Amabile, Agathe Nerot, Julie Choisne, Hélène Pillet, Virginie Lafage, et al.. Alignment of centers of mass of body segments with the gravity line. Computer Methods in Biomechanics and Biomedical Engineering, 2015, 18 (sup1), pp.1870-1871. 10.1080/10255842.2015.1069547 . hal-02458530

\section{HAL Id: hal-02458530 https://hal.science/hal-02458530}

Submitted on 28 Jan 2020

HAL is a multi-disciplinary open access archive for the deposit and dissemination of scientific research documents, whether they are published or not. The documents may come from teaching and research institutions in France or abroad, or from public or private research centers.
L'archive ouverte pluridisciplinaire HAL, est destinée au dépôt et à la diffusion de documents scientifiques de niveau recherche, publiés ou non, émanant des établissements d'enseignement et de recherche français ou étrangers, des laboratoires publics ou privés. 


\title{
Alignment of centers of mass of body segments with the gravity line
}

\author{
C. Amabile ${ }^{a, b}$, A. Nérott ${ }^{a, c}$, J. Choisne ${ }^{a}$, H. Pillet ${ }^{a}$, V. Lafage ${ }^{b}$ and W. Skallia

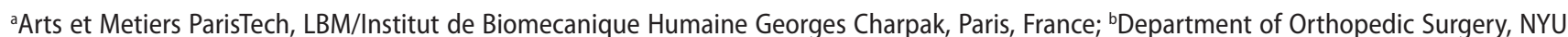 \\ Hospital for Joint Diseases, New York, NY, USA; CUMR_T9406, LBMC Laboratoire de Biomécanique et Mécanique des Chocs, IFSTTAR, Bron, France
}

KEYWORDS Postural alignment; center of masses; gravity line

\section{Introduction}

Sagittal malalignment is associated with increased disability and can lead to postural troubles. The latter is often the result of an inadequate weight distribution on the spine and trigger compensatory mechanisms. No study to date has provided reference values for the alignment of centers of mass (CoM) of different body segments in asymptomatic subjects. The use of a bi-planar X-ray system (Dubousset et al. 2010) combined with $3 \mathrm{D}$ reconstruction of the external body shape (Nérot et al. 2015) allows for computation of the body segments' CoM. The aim of this study was to provide baseline values for the position of each segment's CoM compared to the gravity line (GL) in the sagittal plane.

\section{Methods}

\subsection{Population}

20 asymptomatic volunteers were included (7 males): mean age 25.1 years old [21.4-30.2]; mean body mass index was $21.6 \mathrm{~kg} / \mathrm{m}^{2}[17.7-28.4]$.

\subsection{Radiographs and $3 D$ reconstruction}

Bi-planar head-to-feet radiographs were acquired for each volunteer using the EOS system (EOS Imaging, Paris, France) in the standardized free standing position (FSP) (Faro et al. 2004), with the hands resting on the mandibles (SRS modified FSP) and with shifted feet (Chaibi et al. 2012). 3D reconstruction of the external body shape was performed (Nérot et al. 2015) (Figure 1) and the following segments were obtained: head, thorax (from T1 to T12), arms, forearms, hands, abdomen, thighs, lower legs, and feet.

\subsection{Data analysis}

The following grouped segments were studied: Head; TAA (thorax + arms + forearms + hands + abdomen); Sup_FH (segment over of femoral heads: head + TAA); and Thighs, Lower Legs and Feet (right and left combined).
For each body segment, the sagittal plane offset between the segment's CoM and the whole body CoM (i.e. GL) was calculated. Normality of the data was assessed using Lilliefors test (Lilliefors 1967) (alpha $=0.05)$.

\section{Results and discussion}

Offsets of all considered segments were normally distributed. Figure 1 shows the location of one subject's different CoMs in the sagittal plane; the points' size correlates to the value of the offset from the GL. Figure 2 presents the boxplots of the offsets of the different segments. The offset of the head was the most variable between subjects. The addition of the head in the segment TAA to obtain the segment Sup_FH did not have major impact on the inter-subject variability (SD: $5.1 \mathrm{~mm}$ for both TAA and Sup_FH). This can be explained by the difference in mass of the segments: the head, on average, accounted for $7.3 \%$ of the total body mass, compared to the TAA segment which, on average, accounted for $55.5 \%$ (Table 1). Overall, the head and the lower limbs' segments (thighs, lower legs and feet) are posterior to the GL while other considered segments (Abdomen, TAA, and Sup_FH) were anterior to the GL. In addition, high variability of TAA mass suggests personalized computation of the volume of this segment, particularly in the movement analysis field as it is commonly assessed using regression.

\section{Conclusions}

These preliminary results indicated that the large inter-subject variability of the head has no effect on the position of the CoM of all the segments located above the femoral heads (head + thorax + arms + forearms + hands + abdomen) 


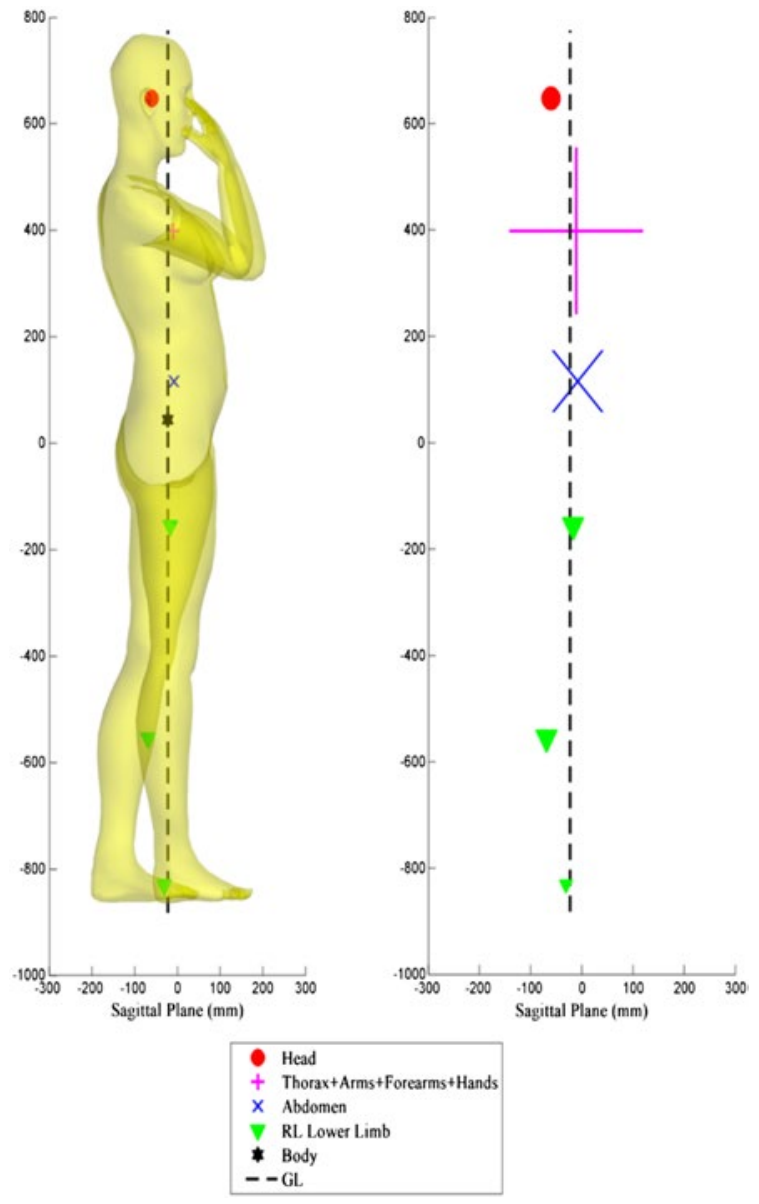

Figure 1. 3D external body shape with different segments' CoM.

Table 1. Offset from GL ( $\mathrm{mm}$ ) and mass (in \% of total body mass) for each segment: mean and standard deviation (SD). RL denotes the mean between right and left sides.

\begin{tabular}{lrrrr}
\hline \multirow{2}{*}{ Segment } & \multicolumn{2}{c}{ Sagittal offset from GL } & \multicolumn{2}{c}{ Mass } \\
\cline { 2 - 5 } & Mean & SD & Mean & SD \\
\hline Head & -11.9 & 20.9 & 7.3 & 0.4 \\
Abdomen & 2.3 & 6.6 & 22.8 & 2.7 \\
TAA & 11.6 & 5.1 & 55.5 & 13.4 \\
Sup_FH & 8.5 & 5.1 & 62.8 & 13.3 \\
RL thighs & -2.6 & 7.8 & 22.6 & 6.0 \\
RL lower leg & -43.0 & 12.2 & 10.5 & 2.6 \\
RL feet & -1.6 & 11.2 & 4.1 & 2.9 \\
\hline
\end{tabular}

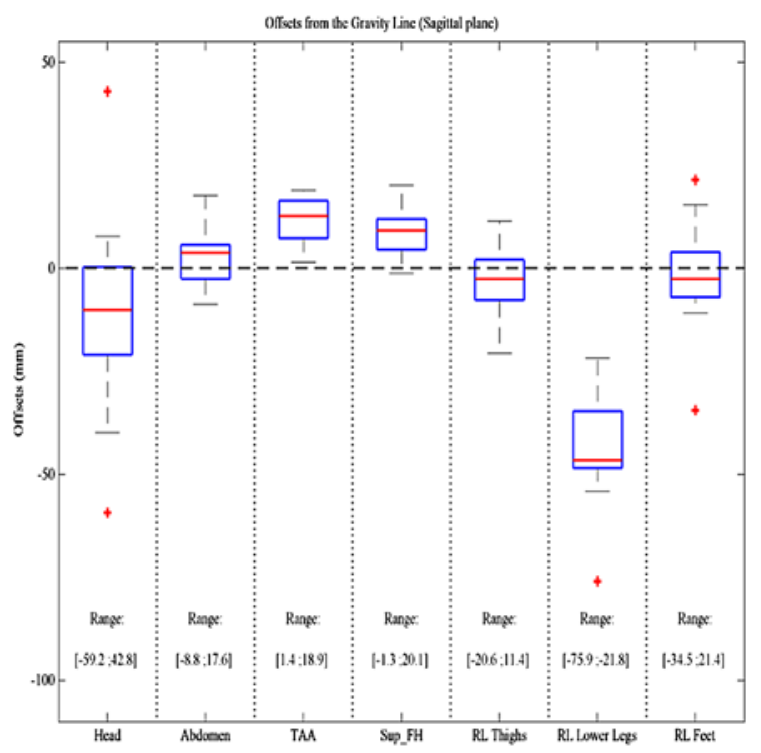

Figure 2. Boxplots of offsets from GL (sagittal plane).

\section{Acknowledgements}

The authors are grateful to the Banque Publique d'Investissement (financial support through dexEOS project), and to the ParisTech BiomecAM chair program in particular COVEA and Société Générale.

\section{References}

Chaibi Y, Cresson T, Aubert B, Hausselle J, Neyret P, Hauger O, de Guise JA, Skalli W. 2012. Fast 3D reconstruction of the lower limb using a parametric model and statistical inferences and clinical measurements calculation from biplanar X-rays. Comput Methods Biomech Biomed Eng. 15:457-466.

Dubousset J, Charpak G, Skalli W, Deguise JA, Kalifa G. 2010. EOS: a new imaging system with low dose radiation in standing position for spine and bone \& joint disorders. J Musculoskelet Res. 13:1-12.

Faro FD, Marks MC, Pawelek J, Newton PO. 2004. Evaluation of a functional position for lateral radiograph acquisition in adolescent idiopathic scoliosis. Spine. 29:2284-2289.

Lilliefors HW. 1967. On the Kolmogorov-Smirnov test for normality with mean and variance unknown. J Am Stat Assoc. 62:399-402.

Nérot A, Choisne J, Amabile C, Wang X, Skalli W. 2015. A new 3D reconstruction method of the body envelope from biplanar Xrays. Submitted to ISB2015 Congress. 